\title{
The dormant period of the apple tree and its change under the influence of destabilization of weather conditions
}

\author{
Elena Tsukanova and Evgeny Tkachev
}

Federal State Budgetary Scientific Institution Federal Scientific Center named after I.V. Michurin, 393774, Michurinsk, Russian Federation

\begin{abstract}
The article presents an analysis of the features of weather conditions in 2020 in the Central Black Earth Region. It determines main deviations from the average long-term values of air temperature and humidity, as well as the distribution of precipitation. It shows the influence of climate change in recent decades, the main of which is the destabilization of the water-temperature regime, on the passage of phenophases in the development of fruit plants, including the dormant period. The article studies various methods of determining the dynamic reaction of the photo-system of apple-tree plants of the varieties Lobo, Zhigulevskoe, Melba, Antonovka, Hani Crisp, Ligol on the stock 62-396 deep rest by non-invasive methods based on the analysis of photosynthetic activity and the intensity of photosynthesis of chlorophyll-containing tissues. It shows the prospects of non-invasive registration of photosynthetic activity of tissues of annual branches for monitoring the period of deep dormancy. It was found that the registration of real parameters of changes in the index of photosynthetic activity during the transition to deep dormancy is possible only in the field. Cut branches of plants, placed in favorable laboratory conditions, show smoothed parameters of fluctuations in the level of fluorescence of chlorophyll-a in assimilation tissues, depending on changes in the functional state of the plant organism.
\end{abstract}

\section{Introduction}

Perennial fruit plants throughout the annual cycle face a wide range of adverse environmental influences during annual cycles.

Plants have evolved to adapt to climatic conditions and have developed different strategies to cope with short or long periods of stress. The period of winter dormancy, on the one hand, is the most important adaptive mechanism for plant survival in winter, on the other hand, it is a necessary condition for the subsequent development of generative buds [1,2]. It is divided into deep and forced, the period of deep dormancy is primarily due to internal changes in plants, while forced - exclusively by external factors. The state of deep dormancy of plants is characterized by numerous internal rearrangements of plants, such as changes in the level of free water in cells, carbohydrate and protein composition, etc.; phenotypically, this is manifested as a lack of plant growth in favorable conditions [1, 3, 4].

It is known that the climatic conditions of cultivation occupy one of the most significant places among the factors influencing the growth and development of fruit plants, and this has become especially noticeable in the last decades. In particular, the lability of the timing of the passage of phenophases has increased, especially at the beginning of the growing season, the beginning and duration of flowering, the beginning and duration of the period of winter dormancy, etc. [5, 6, 7].
According to some researchers, the apple tree is insensitive to changes in the photoperiod, and the shortening of the day does not affect the cessation of growth and the beginning of dormancy, while low temperatures cause the cessation of growth in the apple tree $[8,9]$. It is changed in temperature and day length that should be attributed to the main factors that determine the timing of the entry of apple plants into sleep, its duration, and depth. This work is devoted, among other things, to the study of the influence of the dynamics of the water-temperature regime on the functional reaction of apple plants during preparation and entry into a state of dormancy. The study of the peculiarities of the passage of the dormant period and its relationship with environmental factors are important for obtaining new varieties adapted to future climate changes. At the same time, until now, there is no consensus on the most reliable methods for recording the period of deep dormancy in apple plants; there are attempts to register this period by changing the water balance, expression of genes responsible for the dormant period, and changes in carbohydrate metabolism [10]. All these methods have both advantages and disadvantages - they require a large amount of plant material, a long time or complex equipment, etc. In this regard, one of the most important problems is finding the fastest, easiest to use, and reliable method, pos allowing monitoring changes in the state of plants during the passage of various phases of winter dormancy. 


\section{Materials and methods}

Apple trees of autumn and winter varieties growing in the intensive garden of the Federal Research Center named after I. V. Michurin, located in the city of Michurinsk, Tambov region. To study the timing of the dormant period, 8-year-old apple trees of the varieties Lo-bo, Zhigulevskoe, Melba, Antonovka, Hani Crisp, Ligol were used on the rootstock 62-396.

The timing of the entry of plants into and out of dormancy was determined using various methods:

the standard technique of Y. S. Nesterov [11].

contact monitoring of the physiological state of plants (in terms of the intensity of photosynthesis and gas exchange) using a portable gas analyzer CIRAS2 (PP Systems, USA),

monitoring of the activity of the photosystem-2 of chlorophyll-containing tissues (in terms of Fv / Fm the magnitude of the induction of variable fluorescence of chlorophyll-a in assimilation tissues according to the method of Genty et al. [12], adapted for fruit plants by E. M. Tsukanova [13]

The monitoring of the water-temperature regime was carried out according to the data of the Michurinsk agrometeorological station located in the study area.

Statistical data processing was carried out using analysis of variance using Microsoft Excel 2013 software.

\section{Results and Discussion}

One of the main negative changes in weather conditions in the middle zone of horticulture is the destabilization of the water-temperature regime, and, especially, during the most significant periods for fruit plants [6, 7]. This causes, among other things, a change in the duration and a shift in the timing of the passage of phenophases: an abnormally early start of the growing season, a shift in the timing of flowering, a delay in the growing season in the autumn, etc. late entry of plants into a state of deep dormancy, and its earlier end. All this leads to an increased risk of winter damage to apple plants caused by abiotic stressors.

In terms of the hydro-thermal regime, 2020 was no exception to the trend of weather anomalies in recent decades. Winter period 2019-2020 differed in rather high air temperatures (the average air temperature in December - February was ...- $1.3^{\circ} \mathrm{C}$ ) with minimal daily drops, however, already in March, the first anomalies were noted - the average daily air temperatures were 6$13^{\circ} \mathrm{C}$. With higher average annual values, and the maximum temperatures reached values of $+14.6 \ldots+$ $17.6^{\circ} \mathrm{C}$ starting from March 8 . At the same time, the amount of precipitation was more than $50 \%$ lower than the mean annual values. Frosts on March 15-17 and 2125 had a significant negative effect on plants (the minimum air temperature reached ... $\left.-3.4 \ldots-6.8^{\circ} \mathrm{C}\right)$. It should be noted that in the third decade, precipitation was practically absent, and the air humidity fluctuated within 28-36\% (the norm for this period was 84\%). All the above had a significant impact on the development of plants. The water temperature regime in April and May was quite difficult for plants - so, in early April, the minimum air temperature was $\ldots-7.8 \ldots-3.4^{\circ} \mathrm{C}$. In total, 13 days with negative night air temperatures were noted in April, however, significant daily temperature drops had the greatest negative impact on black currant plants (the difference between day and night temperatures reached $14-18^{\circ} \mathrm{C}$ ), as well as the alternation of warm (with an average daily air temperature of $+12-\ldots+$ $15^{\circ} \mathrm{C}$ ) and cold (with a temperature of $+2 \ldots+4^{\circ} \mathrm{C}$ ) periods. A similar phenomenon was observed in May.

Low $\left(6-10^{\circ} \mathrm{C}\right.$ lower than average annual values) average daily temperatures against the background of average and high air humidity in June, and then alternation of hot (with a maximum air temperature of up to $+36.7^{\circ} \mathrm{C}$ ) and cool (with a maximum air temperature of $+18,8 \ldots+22.7^{\circ} \mathrm{C}$ ) periods. All the above provoked a shift in the phenophase in the development of apple plants - an abnormally early start of the growing season, a prolonged flowering period, late dates of the onset of fruit formation, etc.

No less significant influence on the state of plants, their preparation for winter, and the risk of possible winter damage was exerted by the water-temperature regime of August - October. A feature of this period in 2020 was the alternation of hot (with air temperatures up to $32^{\circ} \mathrm{C}$ ) and cool (up to $8.4^{\circ} \mathrm{C}$ ) periods, a large difference between day and night temperatures (the amplitude of the daily difference in air temperatures significantly exceeded average long-term values and reached $16-18^{\circ} \mathrm{C}$ ). In addition, there was an almost complete absence of precipitation at anomalously low (up to 23\%) air humidity (Fig. 1, 2).

Most of the apple varieties cultivated in the Central Black Earth Region were bred in the second half of the last century; therefore, their hereditary potential is most adapted to the climatic conditions of that period, which leads to significant failures in the response of functional systems plants for climate change.

In connection with the above, the so-called "classical" methods of study do not always objectively reflect the time of entry and exit of plants from a state of deep dormancy. In addition, the buds of cut branches in winter may bloom earlier than on whole plants or not bloom at all due to frost damage, low humidity in the room, degree of illumination, etc. 


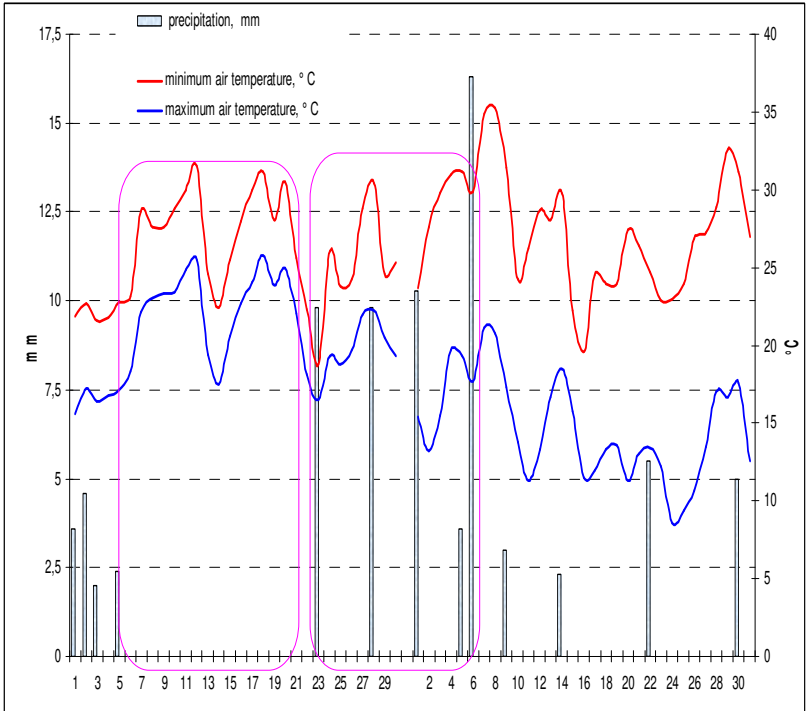

Fig. 1. Maximum and minimum air temperatures and precipitation in June-July 2020

After defoliation in the summer-autumn period, the regrowth of leaves may depend both on the weather conditions of this time, and on the proportion of removed leaves on the plant. Under unfavorable weather conditions - low or high air temperatures, soil drought, etc., leading to forced dormancy of plants, the regrowth

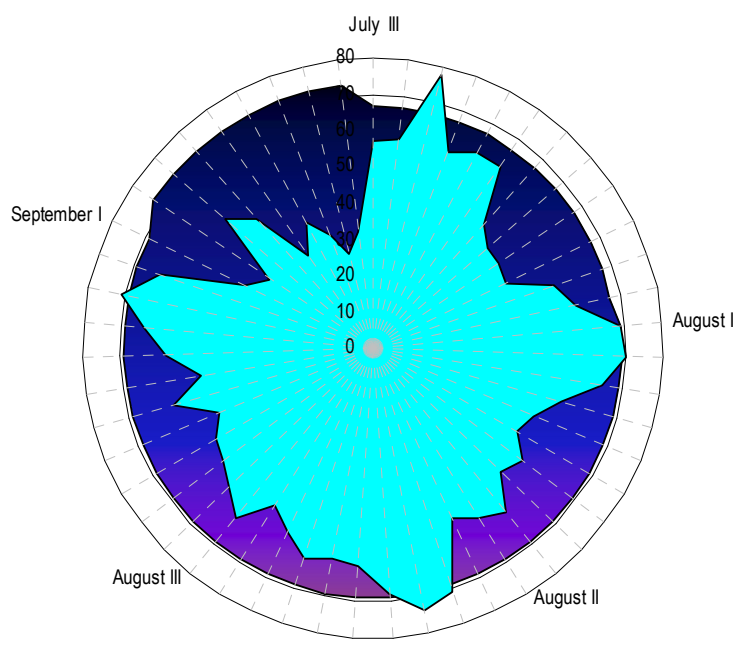

— air humidity rate $\square$ air humidity 2020

Fig.3. Air humidity in the third decade of August - the first decade of September 2020 in comparison with the average long-term norm

We tried to determine the timing of the entry into the dormancy of apple plants by methods of assessing the work of the photosynthetic apparatus of chlorophyllcontaining tissues.

Contact monitoring of the physiological state of plants (in terms of the intensity of photosynthesis and gas exchange) using a portable gas analyzer CIRAS-2 (PP Systems, USA) showed that in summer the level of photosynthesis intensity in leaves was $15-23 \%$

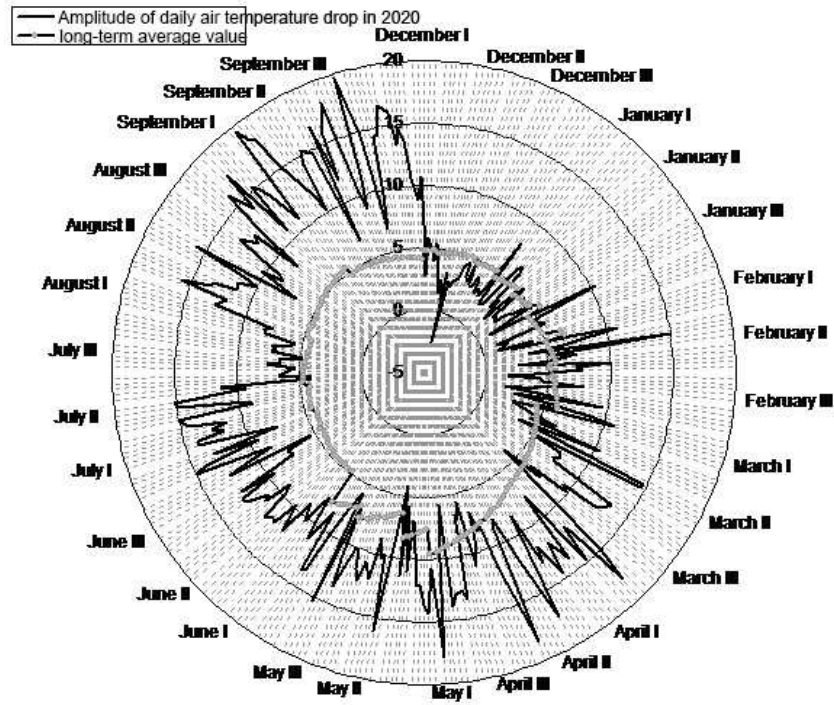

Fig. 2. Amplitude of daily air temperature drop in 2020

of leaves may not occur.

In our opinion, it was the high air temperature and abnormally dry conditions in the third decade of July the first decade of September 2020 that caused the termination of growth processes after defoliation in all studied apple varieties (Fig. 3, 4).

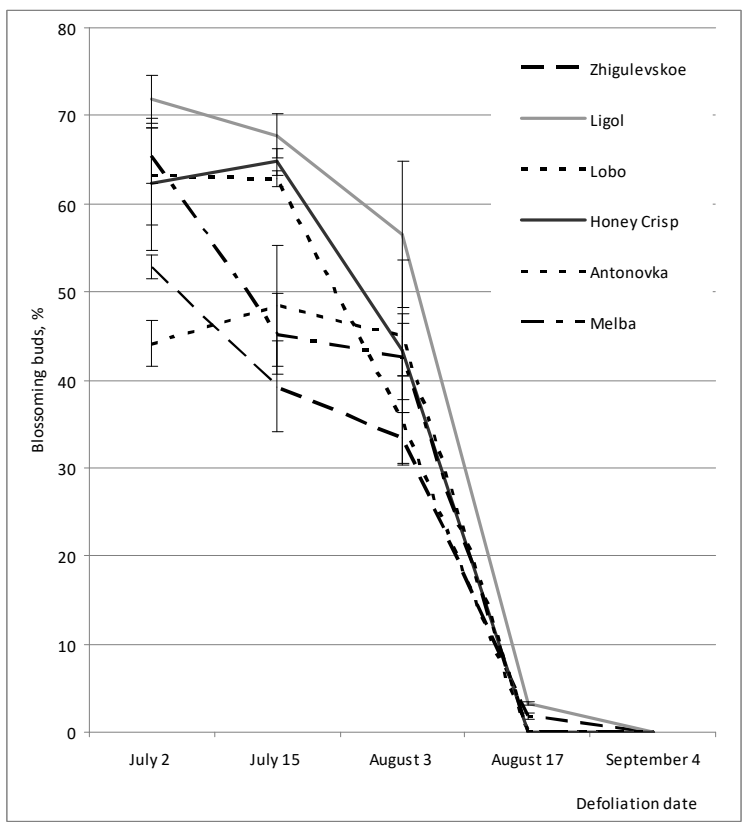

Fig. 4. The proportion of blossoming buds after defoliation

(depending on varieties) below the average annual values. This is due to the difficult weather conditions of the growing season in 2020 - significant (up to $18^{\circ} \mathrm{C}$ ) daily air temperature drops, alternation of cool (with an average daily temperature of $14-18^{\circ} \mathrm{C}$ ), and humid periods with dry and hot (average daily air temperature reached values $28^{\circ} \mathrm{C}$ ), frequent dry winds.

However, despite the difficult conditions of temperature and water regimes, from the third decade of July, there was a seasonal increase in the intensity of 
photosynthesis of plant leaves, recorded by the level of assimilation of carbon dioxide (Fig. 5).

In late September and early October, this level approached the maximum for the growing season. The highest rates in this period were characterized by the introduced varieties Ligol and Honey Crisp, reaching the level of carbon dioxide assimilation, respectively, 12.85 and $14.6 \mu \mathrm{mol} / \mathrm{m}^{2} / \mathrm{s}-1$. The intensive work of the photosynthetic apparatus in mid-October may indicate that the trees have not yet entered a period of deep dormancy.

To estimate the timing of the onset of deep dormancy, we used an analysis of the dynamics of photosynthetic activity of chlorophyll-containing tissues of leaves and branches according to the Fv / Fm parameter (the level of fluorescence induction of chlorophyll-a in assimilation tissues).

High air temperatures in September (up to $+32^{\circ} \mathrm{C}$ in the first decade and up to $24.1{ }^{\circ} \mathrm{C}$ in the third) and October (up to $+21^{\circ} \mathrm{C}$ ) against the background of practically optimal values of air humidity $(73-84 \%$ at the optimum for this period $81 \%$ ) provided a high level of photosynthetic activity in all studied apple varieties ( $\mathrm{Fv} /$ Fm 25-36\% higher than optimal values) after low (23$28 \%$ lower than optimum) values of the indicator in July - August.

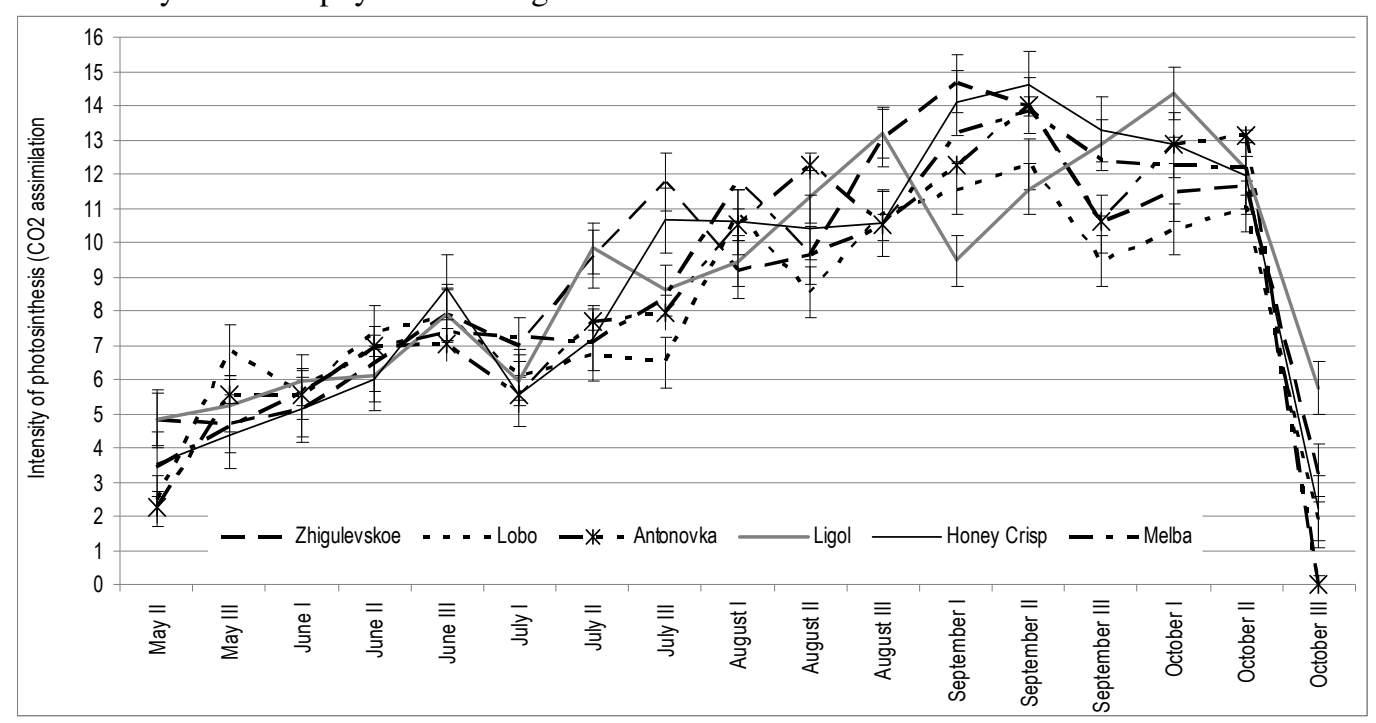

Fig.5. Intensity of photosynthesis $\left(\mathrm{CO}_{2}\right.$ assimilation, $\mu \mathrm{mol} / \mathrm{m}^{2} / \mathrm{s}^{-1}$ ) of leaves of apple varieties

Approximation of the obtained data made it possible to reveal the general trend of changes in the photosynthetic activity of tissues in the period from the third decade of September to the second decade of November in all studied varieties (Fig. 6). The data obtained may indicate the restructuring of the functional systems of plants as a result of exposure to low negative air temperatures in the second decade of October, which led to a sharp inhibition of the processes of photosynthesis. A subsequent increase in air temperature in the third decade of October to $+5-+8^{\circ} \mathrm{C}$ provoked a slight activation of the photosystems; later we observed a stable inhibition of this process, and already in the second decade of November, the Fv / Fm values reached a winter minimum (Fig. 6). This picture illustrates the processes of hardening a plant organism in preparation for entering a state of winter dormancy and subsequent withdrawal into deep dormancy.

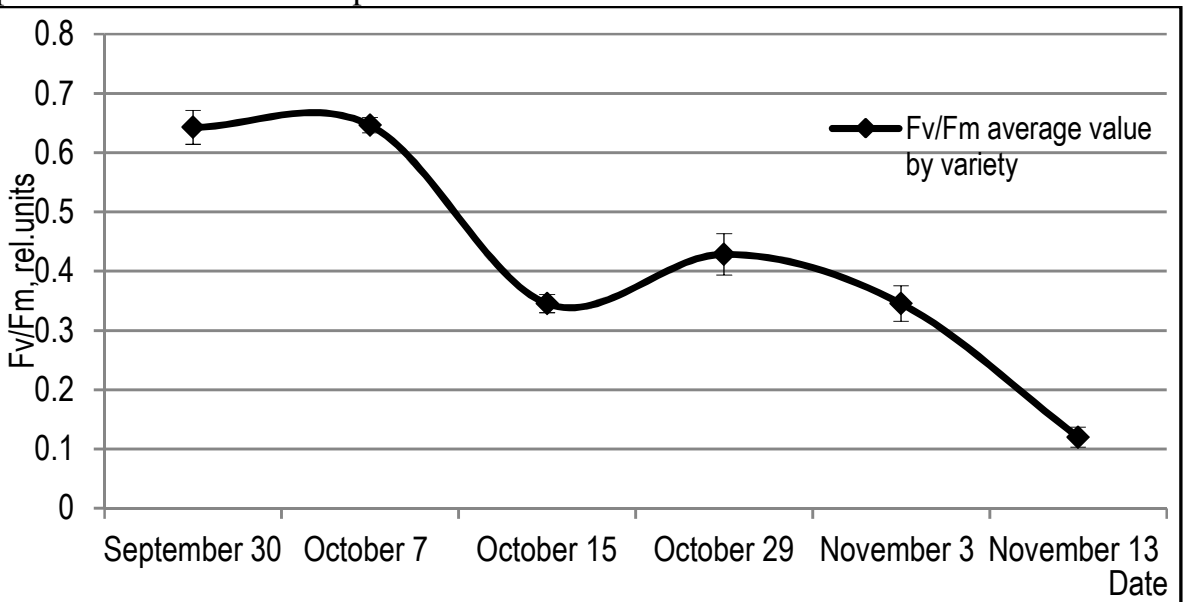

Fig.6. Photosynthetic activity of chlorophyllcontaining tissues of annual branches of apple varieties 
To determine the degree of adequacy of the reflection of the state of photosynthetic activity of chlorophyllcontaining tissues of annual apple branches, depending on the measurement conditions, we carried out a comparative assessment of the results obtained in the garden and under laboratory conditions after cutting (Fig. 7). The measurements were carried out with an IFSR-2 instrument (inductor of variable fluorescence of chlorophyll-la-a) through the cortex.

A detailed analysis of the results of measurements of the activity of photosystem- 2 of apple tree branches made it possible to establish that significant changes in this indicator are noticeable in the field the dynamics of the Fv / Fm indicator reflect the processes occurring in the plant photosystem during the transition to deep dormancy.

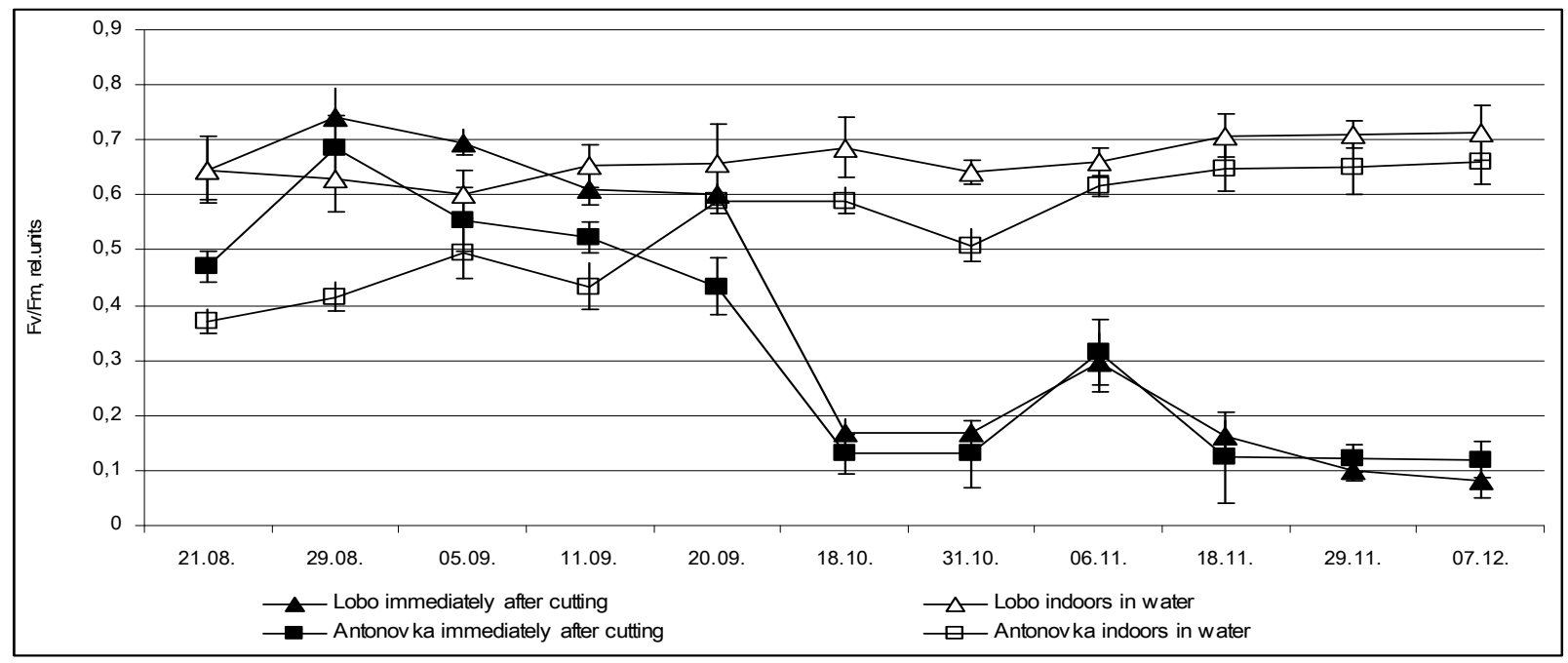

Fig.7. Photosynthetic activity of chlorophyll-containing tissues of annual branches of an apple tree in terms of the induction of variable chlorophyll-a fluorescence in assimilation tissues (Fv / Fm)

Cut branches of plants placed in favorable laboratory conditions do not undergo significant changes in the functional state, as evidenced by the smoothed dynamics of indicators of photosynthetic activity of chlorophyllcontaining tissues for a long time (more than three months).

\section{Conclusion}

Thus, the main distinguishing feature of the entire growing season of 2020 was the significant instability of the water-temperature regime - dry periods with high air temperatures were replaced by moist and cool ones. Deviations of the water-temperature regime of the growing season 2020:

- abnormally high average daily temperatures in March with low air humidity;

- low average daily temperatures against a background of medium and high air humidity in April - June;

- alternation of hot and cool periods in JulyAugust;

- abnormally low air humidity and almost complete absence of precipitation (no more than $10 \%$ of the average annual values) during the period from the third decade of July to the third decade of September;

- high air temperatures against a background of humidity close to optimal, in October-early November, which led to a significant delay in the growing season;

- $\quad$ significant difference between night and day air temperatures.
- abnormal weather conditions led to a change in the rhythm of the phenophase of the apple tree and the timing of the entry of plants into a state of winter dormancy.

In our opinion, non-invasive registration of photosynthetic activity in the tissues of branches is very promising for analyzing the timing of the passage of the dormant period. For an objective assessment, measurements should be carried out directly in the garden or immediately after cutting the branches.

\section{Acknowlegements}

This work was supported by the Russian Foundation for Basic Research (grant 19-016-00016 A "Influence of abiotic stresses on the dormancy period of fruit plants and its non-invasive express monitoring")

\section{References}

1. A. Rohade, R. P. Bhalerao, Trends Plant Sci. 12, 217-223 (2007).

2. C. J. Atkinson, R. M. Brennan, H. G. Jone, Environ Exp Bot. 91, 48-62. (2013)

3. S. Begum, S. Nakaba, Y. Yamagishi, Y. Oribe, R. Funada, Physiol Plant. 147, 46-54 (2007).

4. S. Begum, K. Kudo, Y. Matsuoka, S. Nakaba, Y. Yamagishi, E. Nabeshima, M. H. Rahman, W. D. Nugroho, Y. Oribe, H. O. Jin, R. Funada, Ann Bot. 117, 465-477 (2016)

5. E. E. Cleland, I. Chuine, A. Menzel, H. A. Mooney, M. D. Trends, Ecol. Evol. 22, 357-365 (2007) 
6. E. Tsukanova, E. Tkachev, IOP.: Earth Environ. Sci. 226, 012034 (2019)

7. S. M. Matveev, Y. G. Chendev, A. R. Lupo, J. A. Hubbart, D. A. Timashchuk, Geophys. 174, 1427 (2017)

8. O. M. Heide, A. K. Prestrud, Physiol., 25, 109114 (2005)

9. I. S. Fløistad, A. Granhus, Silva Fenn. 47, 1009 (2013)

10. F. G. Dennis, Hort Science. 38, 347-350 (2003)

11. Y. S. Nesterov, The Dormancy Period of Fruit Crops. (Moscow: Selkhozizdat, 1962)

12. B. Genty, J. M. Briantais, N. R. Baker, Biochimica et Biophysica Acta. 990, 87-92. (1989)

13. E. M. Tsukanova, System for diagnosing the state of fruit plants. (LAPLAMBERT Academic Publishing, 2011) 